\title{
Descriptions of Immature Stages of Trupanea nigricornis and T. bisetosa (Diptera: Tephritidae) from Southern California
}

\author{
KHOUZAMA M. KNIO, RICHARD D. GOEDEN, \\ AND DAVID H. HEADRICK
}

Department of Entomology, University of California, Riverside, CA 92521

\begin{abstract}
Ann. Entomol. Soc. Am. 89(1): 1-11 (1996)
ABSTRACT The immature stages of the sympatric, cryptic species Trupanea nigricornis (Coquillett), a flower head-infesting fruit fly that attacks a wide range of hosts in the Asteraceae in southern California, and $T$. bisetosa (Coquillett), an oligophagous congener that attacks only a few hosts in the tribe Heliantheae, are described and illustrated. Detailed examination with the aid of scanning electron microscopy of the eggs, all 3 instars, and puparia of this taxonomically closely allied generalist and specialist revealed many similarities and very few differences, for instance, most puparia of $T$. nigricornis were shorter and narrower than those of $T$. bisetosa. Therefore, major differences in the host-plant specificities of these cryptic, possibly sibling, species were not reflected by substantial morphological differences among their immature stages.
\end{abstract}

KEY WORDS Trupanea, cryptic species, immature stages, sympatry, taxonomy

THE FLOWER-HEAD INFESTING tephritids Trupanea nigricornis (Coquillett) and T. bisetosa (Coquillett) occur in sympatry in southern California. They are considered cryptic species because adults of both sexes show close morphological resemblance. The males are readily distinguished by the color of the 3rd antennal segments, brown in $T$. nigricornis and yellow in T. bisetosa (Foote 1960, Foote and Blanc 1963, Foote et al. 1993); however, females could not be distinguished until recently. Most (75\%) females are now separated based on the shape of the basal stem of the apical Y-shaped mark in the wing. This stem is thin and distinct in $T$. nigricornis females, but broad and short in $T$. bisetosa females (Cavender and Goeden 1983, Foote et al. 1993). The phylogenetic relationships among Trupanea spp. have not been studied. However, based on wing morphology, the most useful diagnostic character in the genus Trupanea nigricornis and $T$. bisetosa are the closest relatives among the North American species and are probably sibling species (A. L. Norrbom 1993, personal communication). The immature stages of $T$. nigricornis have not been described. T. bisetosa immature stages were briefly described by Cavender and Goeden (1982). We provide detailed descriptions of all preimaginal stages for each of these cryptic species.

\section{Materials and Methods}

The immature stages of $T$. nigricornis were obtained from dissections of flower-head samples of Encelia farinosa Gray, E. fructescens Gray, and $E$. virginensis A. Nelson collected during 1989-1990 from 8 different interior valley locations in Riverside County, CA. The immature stages of $T$. bisetosa were obtained from dissections of flower heads of wild sunflower, Helianthus annuus L., collected from 2 interior valley locations near Riverside in Riverside County: Casa Blanca section of south Riverside in May and August 1989 and October 1990; and along Gilman Springs Road in San Jacinto Valley, $9 \mathrm{~km}$ east of Riverside in November 1989 and October-November 1990.

The ultrastructure of 6 each of eggs, each instar, and puparia of $T$. nigricornis and T. bisetosa was examined with a JEOL JSM-C-35 scanning electron microscope (SEM) in the Department of Nematology, University of California, Riverside. The specimens for SEM were fixed and preserved in $70 \%$ ethanol. Before scanning, they were rehydrated through decreasing serial dilutions of ethanol, washed in distilled water, and postfixed in $2 \%$ osmium tetroxide for $24 \mathrm{~h}$. Afterward, the specimens were washed twice in distilled water, dehydrated in an increasing series of acidulated ethanol dilutions to $100 \%$, and washed twice with $100 \%$ ethanol. Then, they were critical-point dried, mounted on stubs, and coated with a gold-palladium alloy before examination of $15 \mathrm{kV}$ accelerating voltage. Micrographs were prepared using Polaroid $55 \mathrm{P} / \mathrm{N}$ film.

Egg and puparial measurements were obtained by direct measurement of the specimens, larval measurements were obtained by slide-mounting specimens according to the method described by 
Phillips (1946). SEM measurements may show some discrepancies because of specimen shrinkage or nonplanar viewing.

Terminology used in the descriptions of the immature stages of T. nigricornis and T. bisetosa was based on the publications of Carroll and Wharton (1989), Headrick and Goeden (1990, 1991), Goeden and Headrick (1991a, b; 1992), and Goeden et al. (1993). Voucher specimens of T. nigricornis and $T$. bisetosa immatures are stored in the separate research collections of D.H.H. and Jeffrey A. Teerink, Department of Entomology, University of California, Riverside.

\section{Results}

\section{Trupanea bisetosa (Coquillett)}

(Figs. 1-5)

Egg. Smooth, shiny-white, elongate-ellipsoidal (Fig. 1A); $0.73 \pm 0.01 \mathrm{~mm}$ long $(n=20$; range, $0.71-0.80 \mathrm{~mm}$ ), $0.18 \pm 0.001 \mathrm{~mm}$ wide (range, $0.17-0.19 \mathrm{~mm}$ ); anterior end with short, distinct pedicel, $0.03 \pm 0.001 \mathrm{~mm}$ long (range, 0.03-0.04 $\mathrm{mm}$ ), central micropyle (Fig. 1B-1), and 1 or 2 rows of aeropyles (Fig. 1B-2) connected by fine pores (Fig. 1C).

First Instar. White, slightly translucent, cylindrical, truncate at both ends (Fig. 2A); $0.55 \pm 0.01$ $\mathrm{mm}$ long ( $n=20$; range, $0.48-0.60 \mathrm{~mm}$ ), $0.21 \pm$ $0.003 \mathrm{~mm}$ wide (range, $0.20-0.23 \mathrm{~mm}$ ); cephalopharyngeal skeleton averaged $0.12 \pm 0.003(n=$ 6; range, $0.11-0.13) \mathrm{mm}$ long; mouth hooks bidentate (Fig. 2B-1); median oral lobe between mouth hooks (Fig. 2B-2), attached basally to labial lobe (Fig. 2B-3); labial lobe with 2 pores anteriorly; mouth hooks ventral to paired, flattened integumental petals (Fig. 2B-4); anterior sensory lobes dorsal to petals (Fig. 2B-5, 2C), each lobe with 4 sensory organs: terminal sensory organ (Fig. 2C-1), pit sensory organ (Fig. 2C-2), lateral sensory organ (Fig. 2C-3), and supralateral sensory organ (Fig. 2C-4); dorsal sensory organs (Fig. 2C-5) and subdorsal sensilla (Fig. 2C-6) dorsal to anterior sensory lobes; stomal sense organs flat with a single, central pore, laterad of mouth hooks, ventrad of anterior sensory lobes; mesothorax, metathorax, and all abdominal segments each with lateral spiracular complex composed of single spiracle (Fig. 2D-1) and 2 dome-shaped sensilla, each with central papilla (Fig. 2D-2); caudal segment circumscribed by stelex sensory receptors (Fig. 2E-1); intermediate sensory complex ventral to spiracular plates, each composed of single stelex and medusoid sensillum (Fig. 2E-2); posterior spiracular plates bearing 2 rimae (Fig. $2 \mathrm{~F}-1$ ), 4 interspiracular processes (Fig. 2F-2) with $1-4$ branches each, these varying in shape (blade-like narrow apically pointed or broad with dentate margin).

Second Instar. White, cylindrical; cephalopharyngeal skeleton moderately pigmented, 0.34 $\pm 0.02 \mathrm{~mm}$ long ( $n=6$; range, $0.24-0.4 \mathrm{~mm}$ );
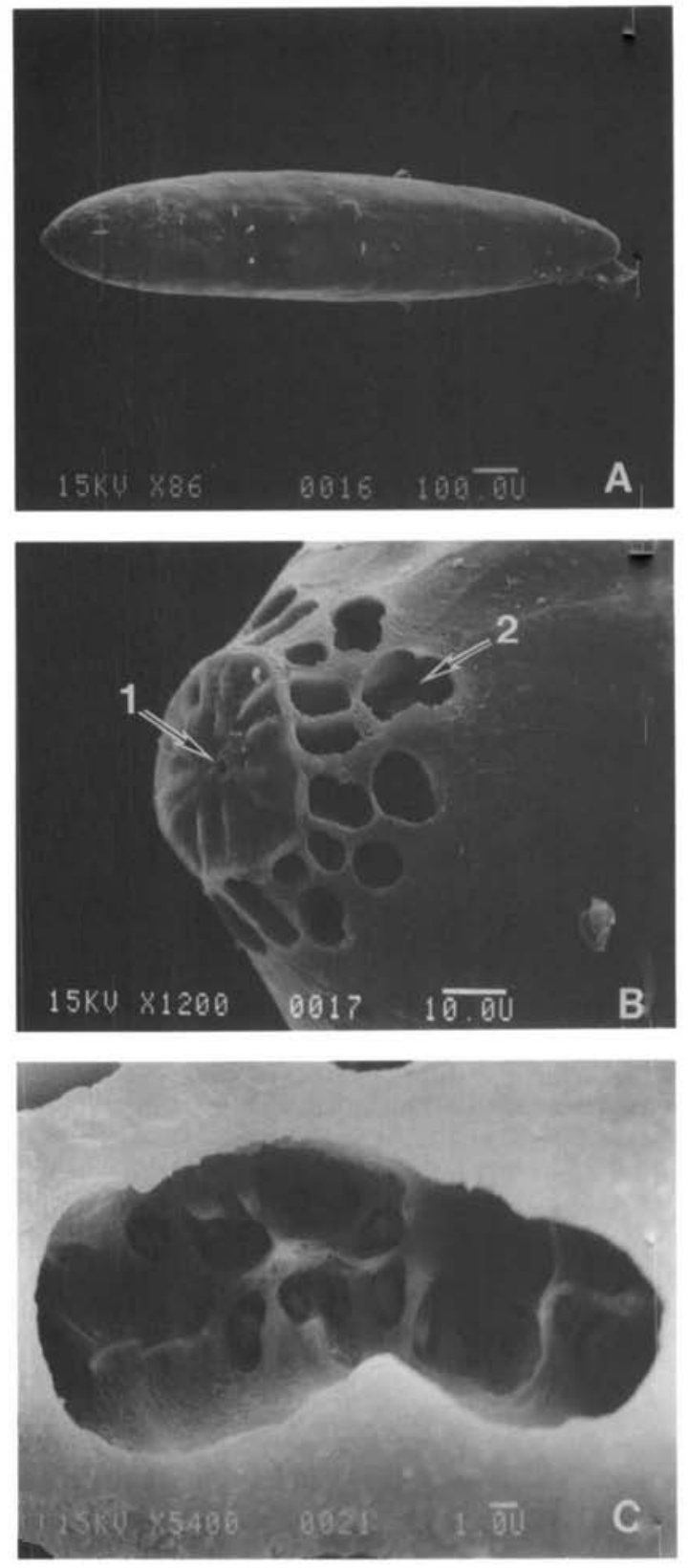

Fig. 1. Egg of T. bisetosa. (A) Habitus; (B) detail of pedicel, (1) micropyle, (2) aeropyle; (C) aeropyle.

mouth hooks tridentate; median oral lobe laterally flattened (Fig. 3A-1), ventral lobe with ventral margin papillate (not shown); gnathocephalon bearing rugose pads with smooth or dentate edges (Fig. 3A-2); anterior sensory lobes as in 1st instar (Fig. 3A-3); stomal sense organ with several sensory papillae (Fig. 3A-4); prothorax with rugose pads on anterior margin, anterior prothoracic spiracles near posterior margin with 4 rounded papillae, each bearing longitudinal slit (Fig. 3B); posterior spiracular plates with 3 spiracular rimae (Fig. 3C-1), 4 interspiracular processes with 6-8 

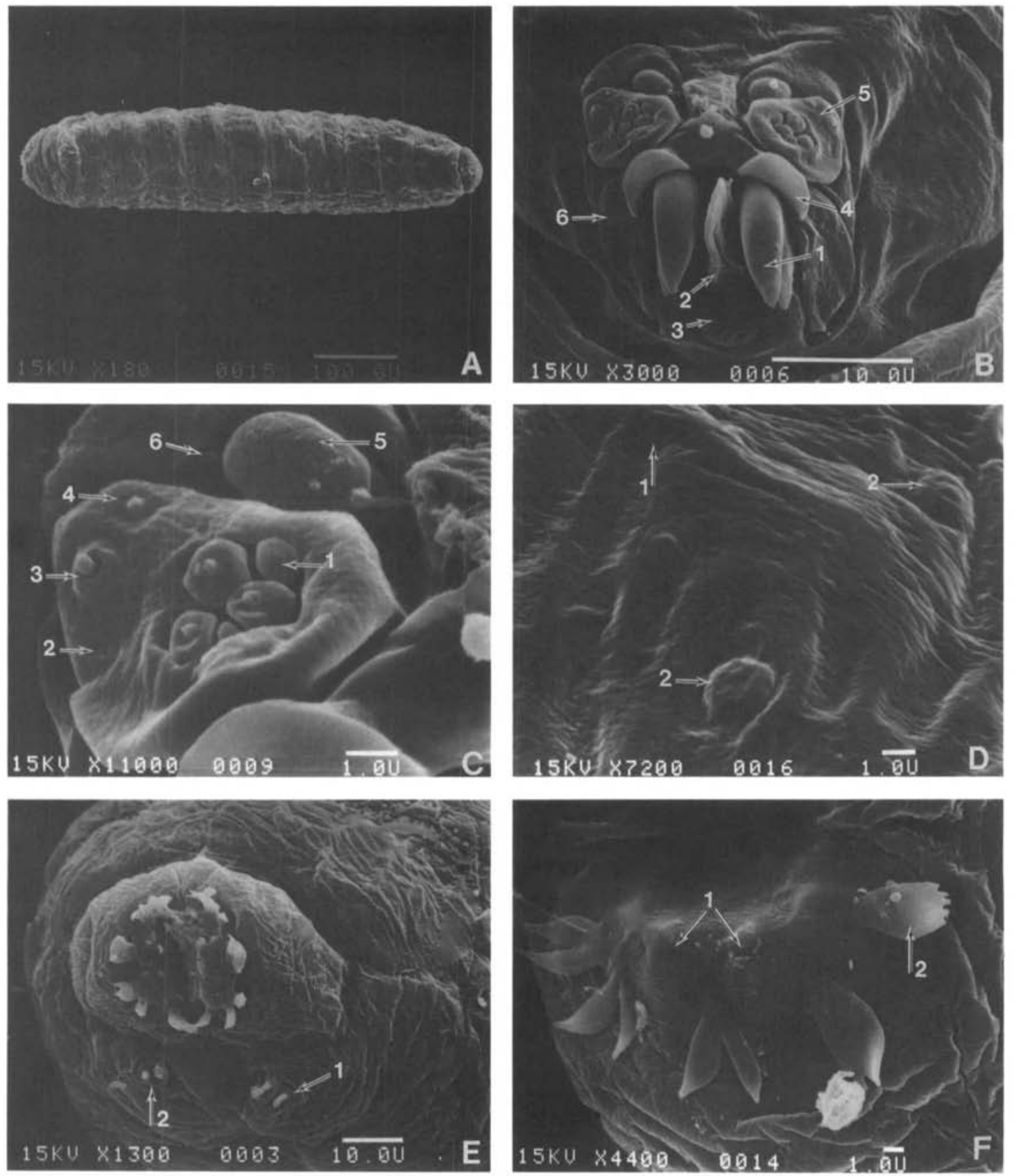

Fig. 2. First instar of T. bisetosa. (A) Habitus, ventral side up, anterior to right; (B) gnathocephalon, dorsal to top, (1) mouth hook, (2) median oral lobe, (3) labial lobe, (4) integumental petal, (5) anterior sensory lobe, (6) stomal sense organ; (C) anterior sensory organ detail, dorsal to top, (1) terminal sensory organ, (2) pit sensory organ, (3) lateral sensory organ, (4) supralateral sensory organ, (5) dorsal sensory organ, (6) subdorsal sensillum; (D) lateral spiracular complex, (1) spiracle, (2) sensillum; (E) caudal segment, (1) stelex sensillum, (2) intermediate sensory complex; (F) posterior spiracular plate, (1) rimae, (2) interspiracular process.

branches (Fig. 3C-2) and a median ecdysial scar (Fig. 3C-3); posterior spiracles surrounded by stelex sensilla, paired intermediate sensory complexes composed of single stelex and medusoid sensillum (Fig. 3C-4).
Third Instar. White, barrel-shaped (Fig. 4A); $2.78 \pm 0.05 \mathrm{~mm}$ long $(n=50$; range, $2.0-3.5 \mathrm{~mm})$, $1.34 \pm 0.02 \mathrm{~mm}$ wide (range, $1.0-1.5 \mathrm{~mm}$ ); cephalopharyngeal skeleton darkly pigmented, 0.39 $\pm 0.01 \mathrm{~mm}$ long, $(n=6$; range, $0.36-0.42)$; mouth 

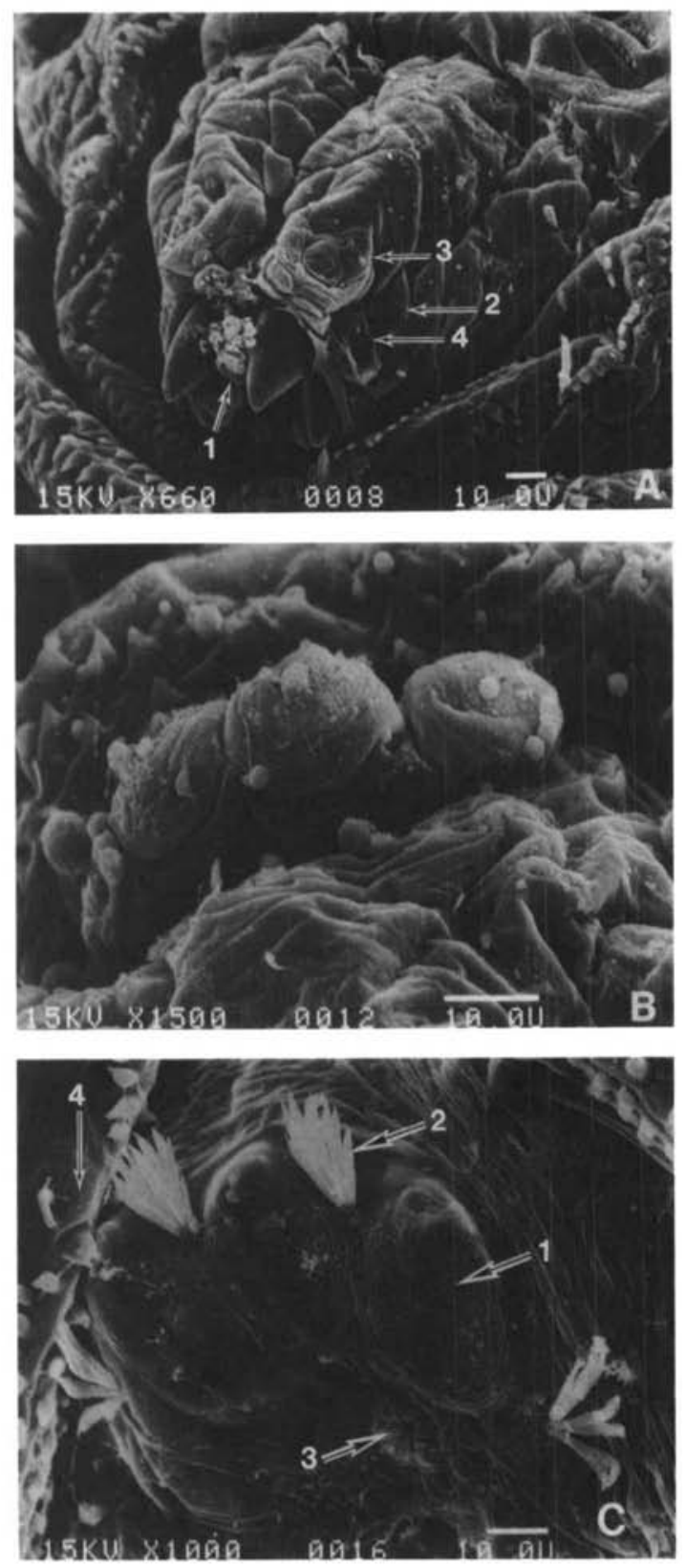

Fig. 3. Second instar of T. bisetosa. (A) Gnathocephalon, (1) median oral lobe, (2) rugose pads, (3) anterior sensory lobe, (4) stomal sense organ; (B) anterior thoracic spiracle; (C) posterior spiracular plate, (1) rima, (2) interspiracular process, (3) median ecdysial scar, (4) intermediate sensory complex.

hooks with 1 apical tooth, 1 subapical tooth, and 1 small median tooth; anterior sensory lobes with 4 sensory organs as described for previous instars (Fig. 4B-1); prothorax circumscribed by rugose pads on anterior margin (Fig. 4B-2), and with dome-shaped sensilla medially (Fig. 4B-3), anterior prothoracic spiracles with 4 rounded papillae, each bearing longitudinal slit (Fig. 4C); mesotho- rax, metathorax, and abdominal segments I-VI with irregular rows of posteriorly directed conical acanthae (Fig. 4D); last 2 segments with several sinuate rows of long conical acanthae directed anteriorly; lateral spiracular complex on all but gnathocephalon and caudal segments, each with open spiracle (Fig. 4E-1), 2 single dome-shaped sensilla with central papilla (Fig. 4E-2), and medial placoid-type sensilla (Fig. 4E-3); posterior spiracular plates bearing 3 oval rimae (Fig. $4 \mathrm{~F}-1$ ), 4 interspiracular processes (Fig. 4F-2) with $6-8$ branches each, and median ecdysial scar (Fig. 4F-3); intermediate sensory complex each composed of single stelex and medusoid sensillum.

Puparium. Black, smooth, barrel-shaped, with truncate ends (Fig. 5A); $3.15 \pm 0.02 \mathrm{~mm}$ long ( $n$ = 135; range, $2.75-3.8 \mathrm{~mm}), 1.4 \pm 0.01 \mathrm{~mm}$ wide (range, 1.2-1.6 $\mathrm{mm}$ ); cephalic end with open thoracic spiracles (Fig. 5B-1); spiracular plates slightly protruding and bearing 3 oval rimae, 4 interspiracular processes with 6-8 branches each, and ecdysial scar (Fig. 5C).

\section{Trupanea nigricornis (Coquillett) \\ (Figs. 6-10)}

Egg. Shiny-white, smooth, elongate-ellipsoidal, (Fig. 6A); $0.72 \pm 0.004 \mathrm{~mm}$ long $(n=72$; range, $0.60-0.80 \mathrm{~mm}$ ), $0.20 \pm 0.001 \mathrm{~mm}$ wide (range, 0.18-0.23 $\mathrm{mm}$ ); anterior end tapered, bearing short, poorly defined pedicel, $0.03 \pm 0.001 \mathrm{~mm}$ long (range, $0.03-0.04 \mathrm{~mm}$ ) with anterior, central micropyle (Fig. 6B-1), and 1 row of aeropyles (Fig. 6B-2); posterior end tapered acutely, smooth.

First Instar. Whitish, slightly translucent, elongate, cylindrical, bluntly rounded at both ends (Fig. 7A); $0.48 \pm 0.11 \mathrm{~mm}$ long $(n=22$; range, $0.30-0.70 \mathrm{~mm}$ ), $0.18 \pm 0.08 \mathrm{~mm}$ wide (range, $0.12-0.25 \mathrm{~mm}$ ); cephalopharyngeal skeleton weakly pigmented, $0.12 \pm 0.003 \mathrm{~mm}$ long $(n=6$; range $0.11-0.13 \mathrm{~mm}$ ); mouth hooks bidentate, with curved apical tooth and subapical tooth (Fig. 7B-1); median oral lobe laterally flattened lying between mouth hooks (Fig. 7B-2), attached (observed by dissections) basally to labial lobe; mouth hooks ventrad of paired, flattened integumental petals (Fig. 7B-3); anterior sensory lobes (Fig. 7B-4) each with 4 sensory organs: terminal sensory organ (Fig. 7C-1), pit sensory organ (Fig. 7C-2), lateral sensory organ (Fig. 7C-3), and supralateral sensory organ (Fig. 7C-4); terminal sensory organ with 5 rounded papillae in papillae in shallow depression; dorsal sensory organs dorsad of anterior sensory lobes (Fig. 7B-5) accompanied laterally by subdorsal sensillum, this consisting of rounded papilla surrounded by slightly raised cuticular ring (Fig. 7B-6); stomal sense organs flat, laterad of mouth hooks and ventrad of anterior sensory lobes, with pore- and cone-shaped sensilla (Fig. 7B-7); caudal segment with 2 conspicuous spiracular plates, each bearing 2 oval rimae (Fig. 

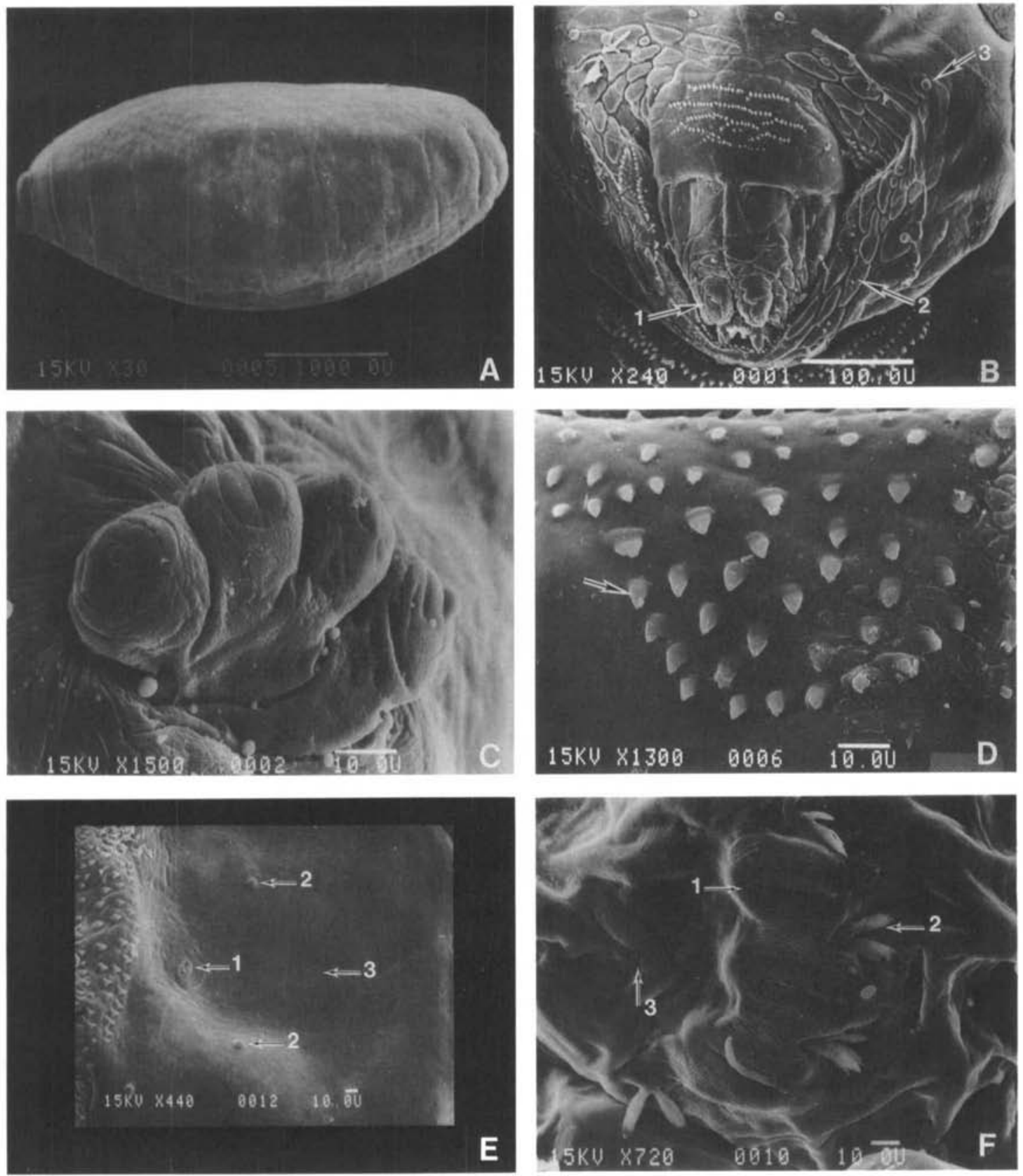

Fig. 4. Third instar of T. bisetosa. (A) Habitus, anterior to left, dorsal to top; (B) gnathocephalon, (1) anterior sensory lobes, (2) rugose pads, (3) prothoracic sensillum; (C) anterior thoracic spiracle; (D) surface acanthae, detail; (E) lateral spiracular complex, (1) spiracle, (2) sensilla, (3) placoid sensillum; (F) posterior spiracular plate, (1) rima, (2) interspiracular process, (3) median ecdysial scar.

7D-1), each with longitudinal slit, and 4 fanshaped interspiracular processes each with 4 broad dentate branches (Fig. 7D-2); paired intermediate sensory complex ventral to spiracular plates, each composed of single stelex and medusoid sensillum (not shown).

Second Instar. White, cylindrical, tapered anteriorly, truncated posterior; moderately pigment- ed cephalopharyngeal skeleton, $0.29 \pm 0.02 \mathrm{~mm}$ long $(n=6$; range, $0.25-0.37 \mathrm{~mm})$; mouth hooks tridentate (Fig. 8A-1), median oral lobe laterally flattened, ventral lobes with ventral margin papillate (Fig. 8A-2); fleshy, flattened projections dorsal to mouth hooks (Fig. 8A-3); stomal sense organ with $\approx 5$ papillate and pit sensoria (Fig. $8 \mathrm{~A}-4$ ); integument surrounding mouth hooks with flattened, 

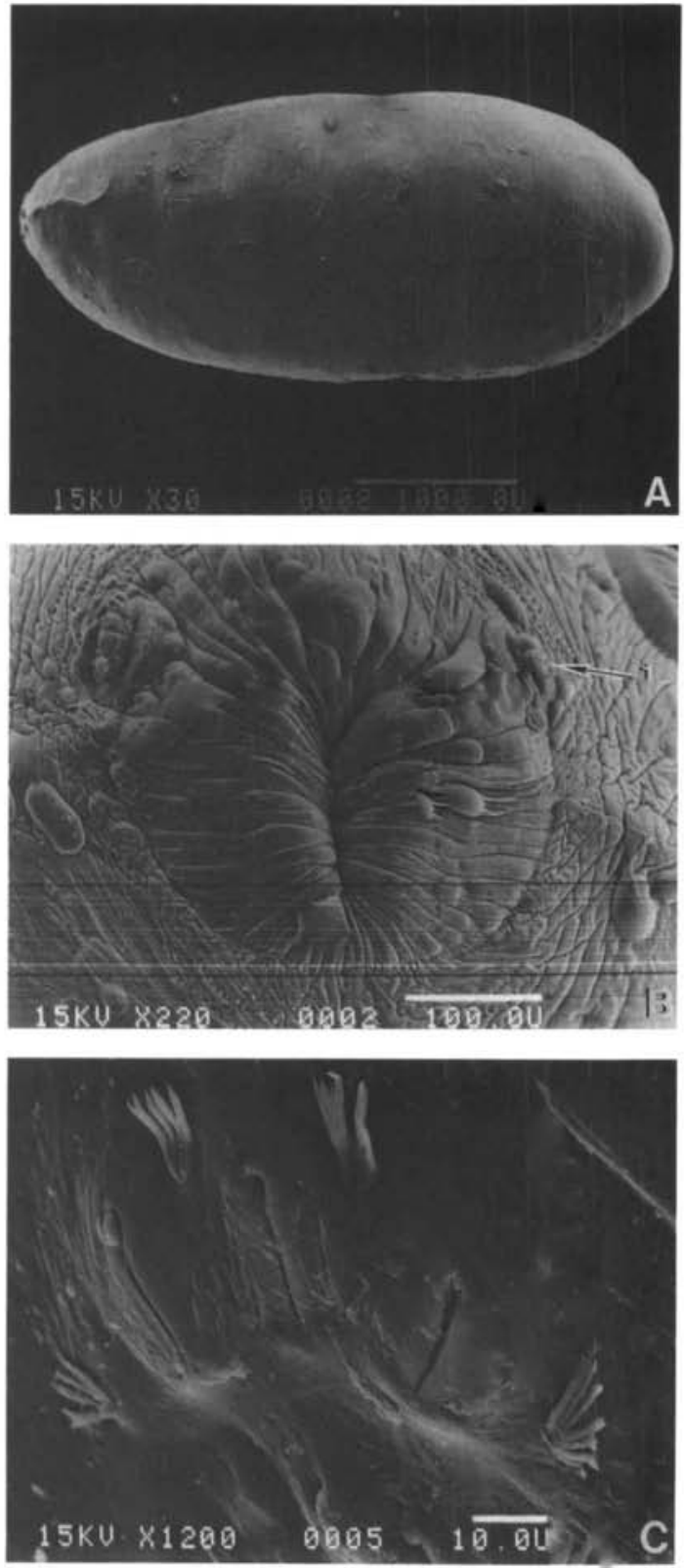

Fig. 5. Puparium of T. bisetosa. (A) Habitus, anterior to left, dorsal to top; (B) anterior end, detail, (1) anterior thoracic spiracle; (C) posterior spiracular plate.

subrectangular pads with dentate or smooth posterior edges (Fig. 8A-5); anterior sensory lobes with 4 sensilla (Fig. 8A-6) as described for 1st instar; dorsal sensory organ a single domed papilla (not shown); with anterior prothoracic spiracles dorsolateral on prothorax near posterior margin, each spiracle bearing 4 rounded papillae, each with single, longitudinal slit (Fig. 8B); posterior spiracular plate with 3 spiracular rimae (Fig. 8C-1), median ecdysial scar (Fig. 8C-2), and 4 branched, fanshaped interspiracular processes, with 5 or 6 branches each (Fig. 8C-3); paired intermediate
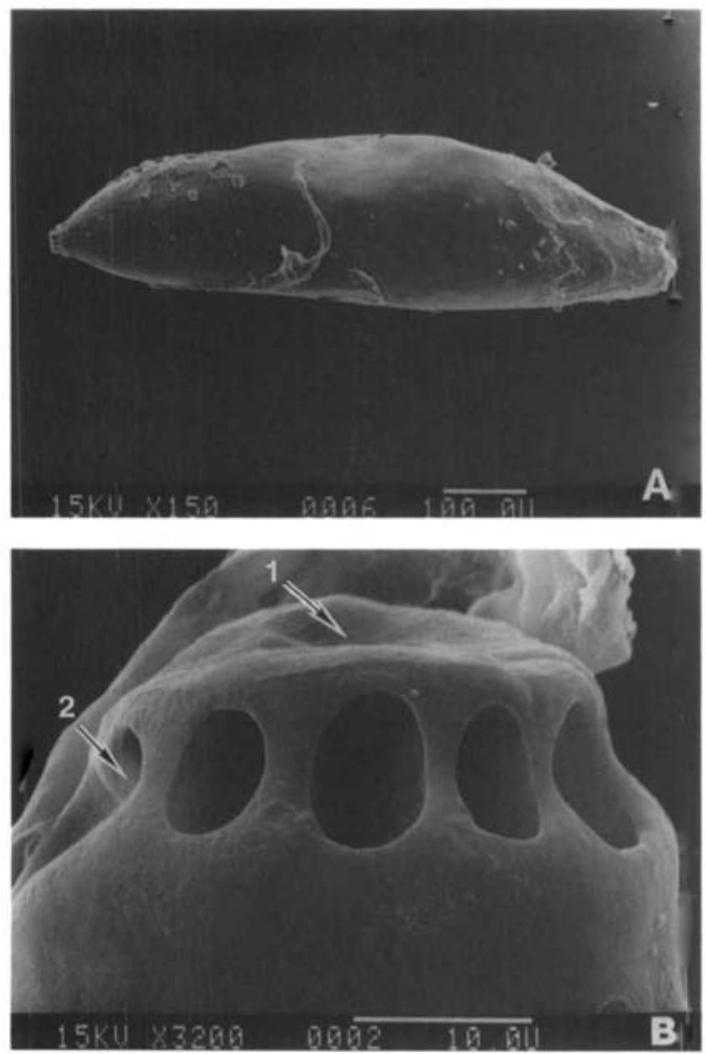

Fig. 6. Egg of T. nigricornis. (A) Habitus, pedicel to left; (B) pedicel, detail, (1) micropyle, (2) aeropyle.

sensory complexes each composed of single stelex and medusoid sensillum.

Third Instar. Creamy white, barrel-shaped (Fig. 9A), $2.66 \pm 0.40 \mathrm{~mm}$ long $(n=30$; range, $1.75-3.25 \mathrm{~mm}$ ), $1.18 \pm 0.17 \mathrm{~mm}$ wide range, 0.80-1.50 mm); cephalopharyngeal skeleton darkly pigmented, averaging $0.36 \pm 0.01 \mathrm{~mm}$ in length ( $n=6$; range, $0.33-0.39 \mathrm{~mm}$ ); mouth hooks with curved apical and subapical teeth, medial tooth at base of subapical tooth prominent (Fig. 9B-1); mouth hooks ventral to several flattened integumental petals (Fig. 9B-2); median oral lobe laterally flattened (Fig. 9B-3); anterior sensory lobes with 4 sensory organs (Fig. 9B-4); stomal sense organs with several sensoria (9B-5); integument of gnathocephalon with rugose, subrectangular pads with dentate margins (Fig. 9B-6); prothorax with rugose pads located on anterior margin (Fig. 9C-1); prothorax circumscribed medially by single row of domed sensilla (Fig. 9C-2); anterior prothoracic spiracles dorsolateral near posterior margin (Fig. 9C-3), with 4 rounded papillae, each with longitudinal slit (Fig. 9D); domed sensilla circumscribing anterior portion of mesothorax (Fig. 9C-4); all thoracic segments and abdominal segments I-VI with several straight rows of acanthae near anterior margins (Fig. 9C-5), acanthae conical, 5-6 $\mu \mathrm{m}$, oriented posteriorly; lateral spi- 

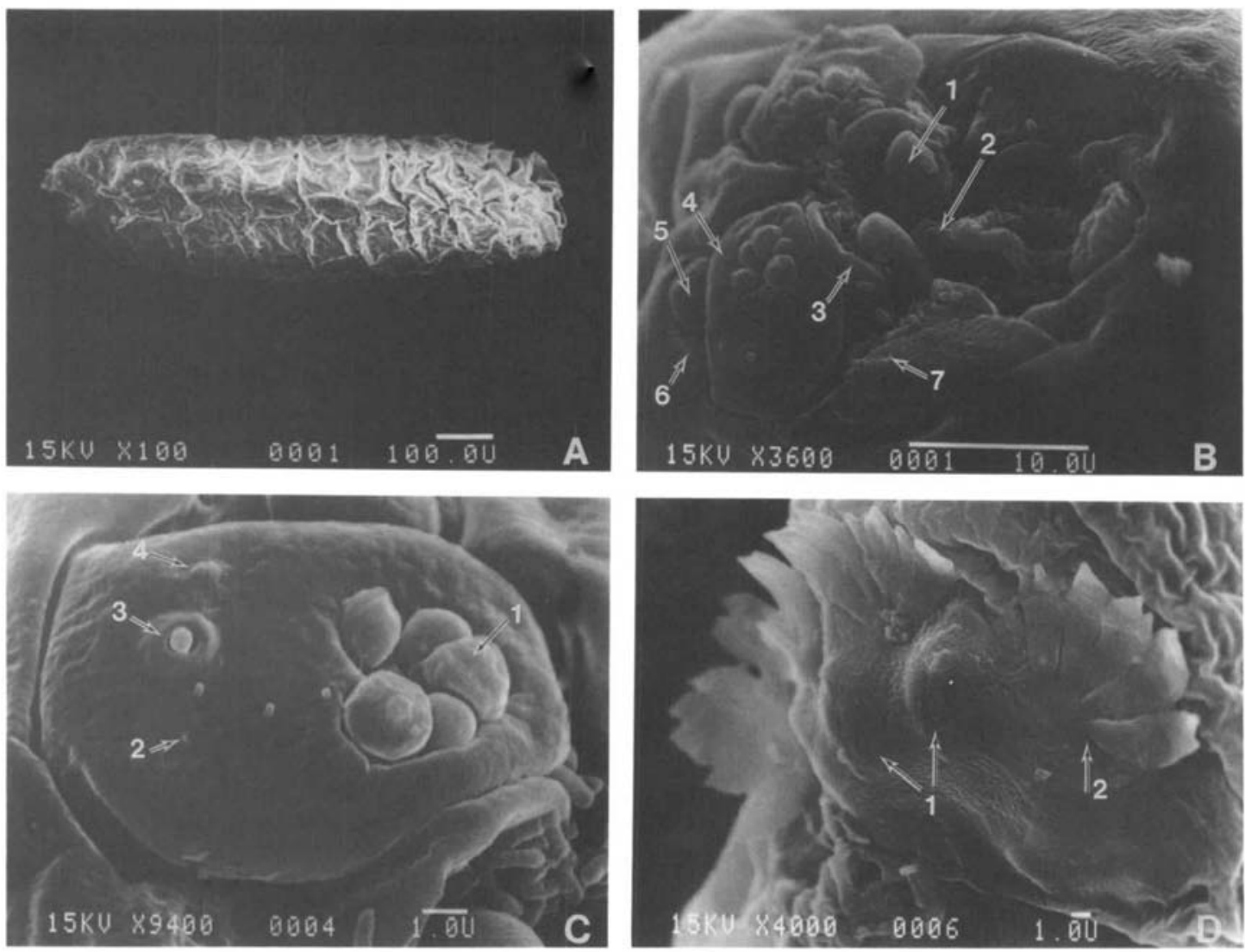

Fig. 7. First instar of T. nigricornis. (A) habitus, anterior to right; (B) gnathocephalon, dorsal to left, (1) mouth hook, (2) median oral lobe, (3) integumental petal, (4) anterior sensory lobe, (5) dorsal sensory organ, (6) subdorsal sensillum, (7) stomal sense organ; (C) anterior sensory lobe, detail, (1) terminal sensory organ, (2) pit sensory organ, (3) lateral sensory organ, (4) supralateral sensory organ; (D) posterior spiracular plate, (1) rimae, (2) interspiracular process.

racular complex on meso- and metathoracic segments and abdominal segments I-VII, each complex with single spiracular opening (Fig. 9E-1) and 2 dome-shaped sensilla with central papilla (Fig. 9E-2); abdominal segments VII-VIII with curved rows of acanthae on posterior margins, acanthae conical, $\approx 9 \mu \mathrm{m}$ long and oriented anteriorly (Fig. 9F-1); caudal segment bearing 2 posterior spiracular plates each with 3 rimae, $0.034 \mathrm{~mm}$ long (Fig. 9F-2), 4 branched interspiracular processes with 3-6 branches each (Fig. 9F-3), and a median ecdysial scar (Fig. 9F-4); plates surrounded by dorsal, ventral, and lateral sensoria (Fig. 9F-5); intermediate sensory complex each composed of single stelex and medusoid sensillum (Fig. 9F-6).

Puparium. Shiny-black, smooth, cylindrical, barrel-shaped, narrow cephalad and blunt posteriad (Fig. 10A); $2.8 \pm 0.01 \mathrm{~mm}$ long $(n=310$; range, $2.2-3.3 \mathrm{~mm}$ ) and $1.3 \pm 0.002 \mathrm{~mm}$ wide (range, $1.0-1.5 \mathrm{~mm}$ ); anterior end invaginated (Fig. 10B-1); anterior prothoracic spiracle papillae protruding with slits open (Fig. 10B-2); posterior spiracular plates darkly pigmented, slightly pro- truding; each bearing ecdysial scar, 3 oval rimae, and 4 interspiracular processes with 3-6 branches each (Fig. 10C-1, 2, 3, respectively).

Comments. Sexually dimorphic adults of $T$. $n i-$ gricornis and T. bisetosa are distinguishable (Cavender and Goeden 1983, Foote et al. 1993). Their immature stages, however, are very similar in their external anatomy with only minimal differences observed.

The pedicel of T. nigricornis eggs only slightly protrudes and in all specimens examined has a single row of aeropyles; $T$. bisetosa eggs often have 2 rows of aeropyles.

The lateral spiracular complex was observed on segments TII-AVII on T. bisetosa 1st instars. Lateral spiracles were not observed on T. nigricornis; however, $T$. nigricornis lst instars were dissected from plants and were often covered with plant exudates. T. bisetosa lst instars were hatched from eggs held in petri dishes with moistened filter paper, and thus remained clean. We presume that lateral spiracles in $T$. nigricomis are present.

Interspiracular processes on the posterior spiracular plates of $T$. bisetosa lst instars are variable 

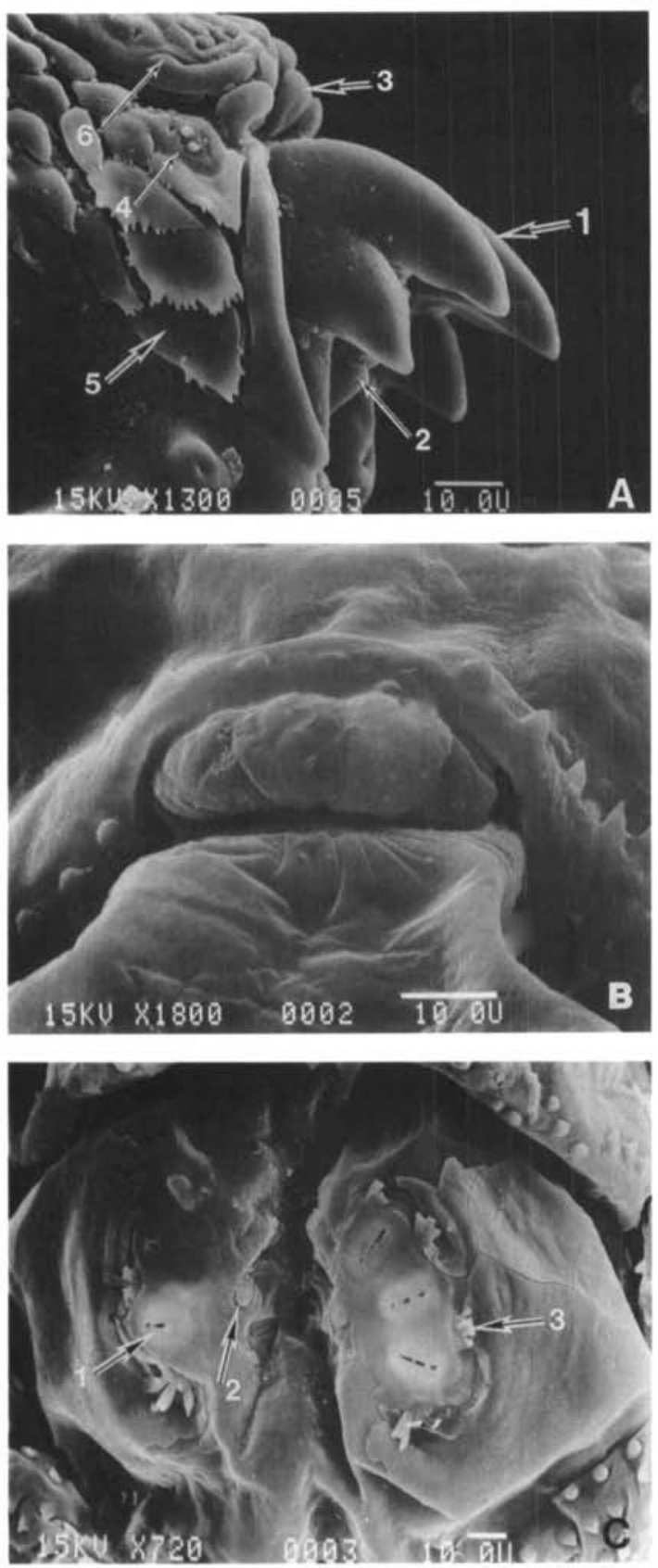

Fig. 8. Second instar of T. nigricornis. (A) Gnathocephalon, (1) mouth hooks, (2) median oral lobe, (3) integumental petals, (4) stomal sense organ, (5) rugose pads, (6) anterior sensory lobe; (B) anterior thoracic spiracle; (C) posterior spiracular plate, (1) rima, (2) median ecdysial scar, (3) interspiracular process.

among individuals, having $1-4$ branches, and each branch being narrow and pointed, or broad with a dentate margin. The processes on $T$. nigricornis all appear to be 4-branched, broad, and dentate.

Interspiracular processes of $T$. bisetosa 2 nd instars have 6-8 branches each, whereas $T$. nigricornis 2 nd instars have 5-6 branches each. Inter- spiracular processes of $T$. bisetosa and $T$. nigricornis 3rd instars have between 3 and 8 , narrow, pointed branches each, the number of branches varying among individuals; however, the branches on $T$. bisetosa 3rd instars are slightly narrower.

Puparia of T. nigricornis are shorter and narrower on average than those of $T$. bisetosa, but their size ranges overlap. Moreover, the sizes of $T . n i$ gricornis puparia varied according to the size of the flower heads of their different hosts (K.M.K. and R.D.G., unpublished data).

\section{Discussion}

The eggs of $T$. nigricornis and T. bisetosa are similar in shape to the eggs of other Trupanea species, for example, T. californica Malloch (Headrick and Goeden 1991), T. conjuncta (Adams) (Goeden 1987), and T. imperfecta (Coquillett) (Goeden 1988). They also are similar in shape to a taxonomically related gall-former, Tephritis baccharis (Coquillett) (Goeden and Headrick 1991a), and to the facultative stem-mining/flower-head infesting species, Tephritis arizonaensis Quisenberry (Goeden et al. 1993).

Sensoria on the anterior sensory lobes are similar in T. nigricornis and T. bisetosa, as are the dorsal sensory organs. A subdorsal sensillum observed on $T$. nigricornis and T. bisetosa may be homologous to 1 of the 3 pit sensilla described by Carroll and Wharton (1989) near the antenna of the Mexican fruit fly, Anastrepha ludens (Loew). This particular sensillum has not been observed in other tephritid species examined by us to date, and its presence or absence should be confirmed in all future descriptions.

The lateral sensory complex was first described in 3rd instars of the tephritine, Trupanea californica (Headrick and Goeden 1991). Since then, all tephritine species examined have been reported as having the lateral spiracular complex. However, the lateral spiracular complex has not previously been observed in 1st instars, although its presence was predicted (Headrick and Goeden 1991). The difficulty in observing these small spiracles is compounded because most larvae examined were dissected from plant material, and thus plant exudates and debris often obscure thorough examination. Early instars also are prone to shrinkage during the process of fixation for SEM, thus making observations difficult. Confirmation of the presence of the lateral spiracular complex in all larval stages of $T$. bisetosa provides impetus for confirmation in other tephritid species. Trypetine species have been reported or observed to have lateral spiracles (A. ludens, Carroll and Wharton [1989]; Bactrocera dorsalis Hendel \& Ceratitis capitata [Wiedemann], D.H.H., and R.D.G., unpublished data), but their presence in all instars, again, needs confirmation. 

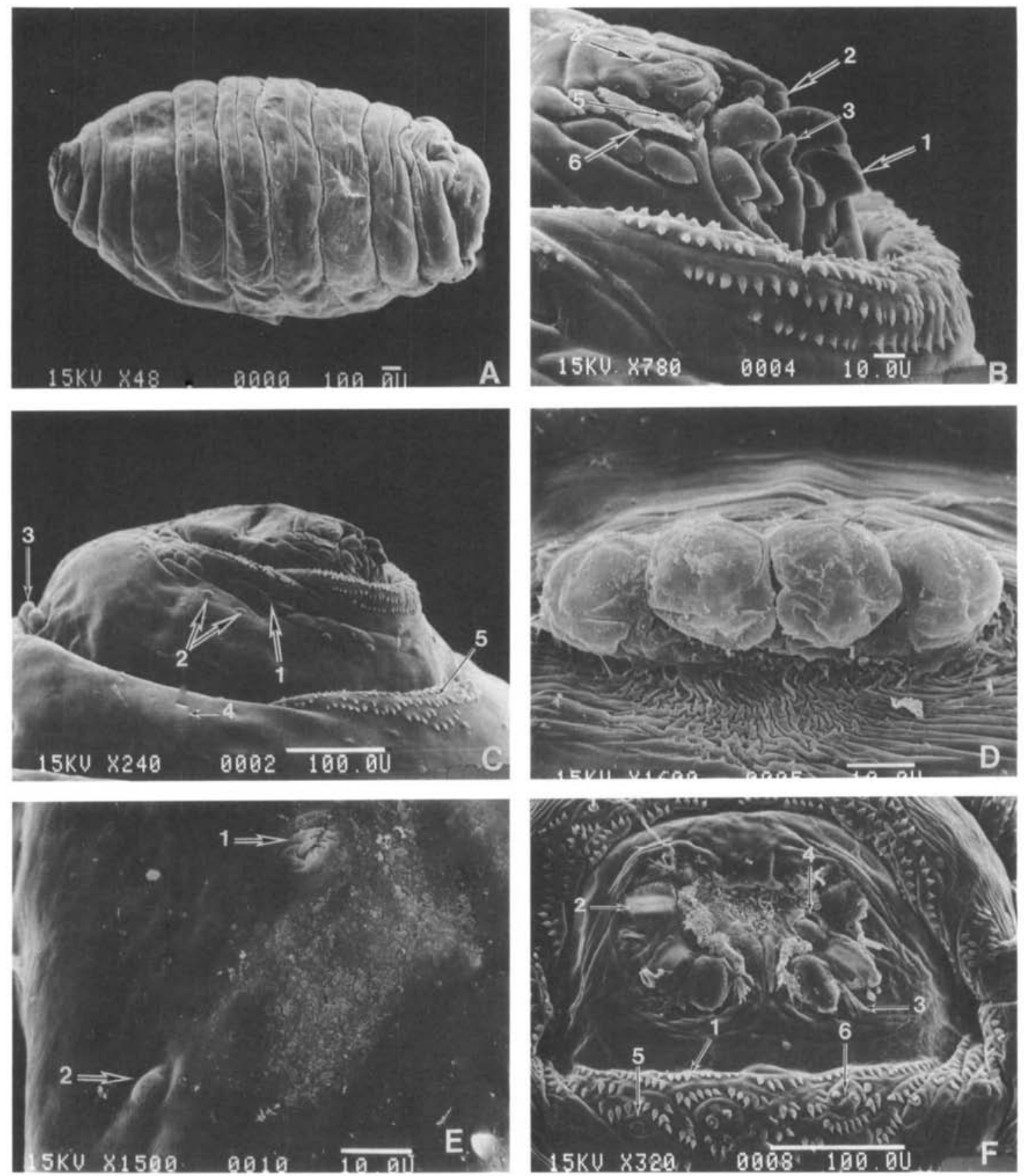

Fig. 9. Third instar of T. nigricornis. (A) Habitus anterior to left, ventral to top; (B) gnathocephalon, (1) mouth hook, (2) integumental petal, (3) median oral lobe, (4) anterior sensory lobe, (5) stomal sense organ, (6) rugose pads; (C) anterior end, (1) rugose pads on prothorax, (2) domed sensilla, (3) anterior thoracic spiracle, (4) domed sensillum on mesothorax, (5) acanthae; (D) anterior thoracic spiracle; (E) lateral spiracular complex, anterior to right, (1) spiracle, (2) sensillum; (F) caudal segment, (1) acanthae, (2) rima, (3) interspiracular process, (4) median ecdysial scar, (5) stelex sensillum, (6) intermediate sensory complex.

Trupanea bisetosa has a limited host range that does not overlap with the wide host range of $T$. nigricornis. This suggests that these 2 species either once shared a common ancestor and diverged in their host ranges or 1 species evolved from the other. The morphological similarity be- tween $T$. nigricornis and $T$. bisetosa immature stages shows that the ability to feed and survive on new hosts does not present a major barrier to host-range expansion or host-shifting by either species. No major differences in mouthpart structures or sensory organs associated with feeding 

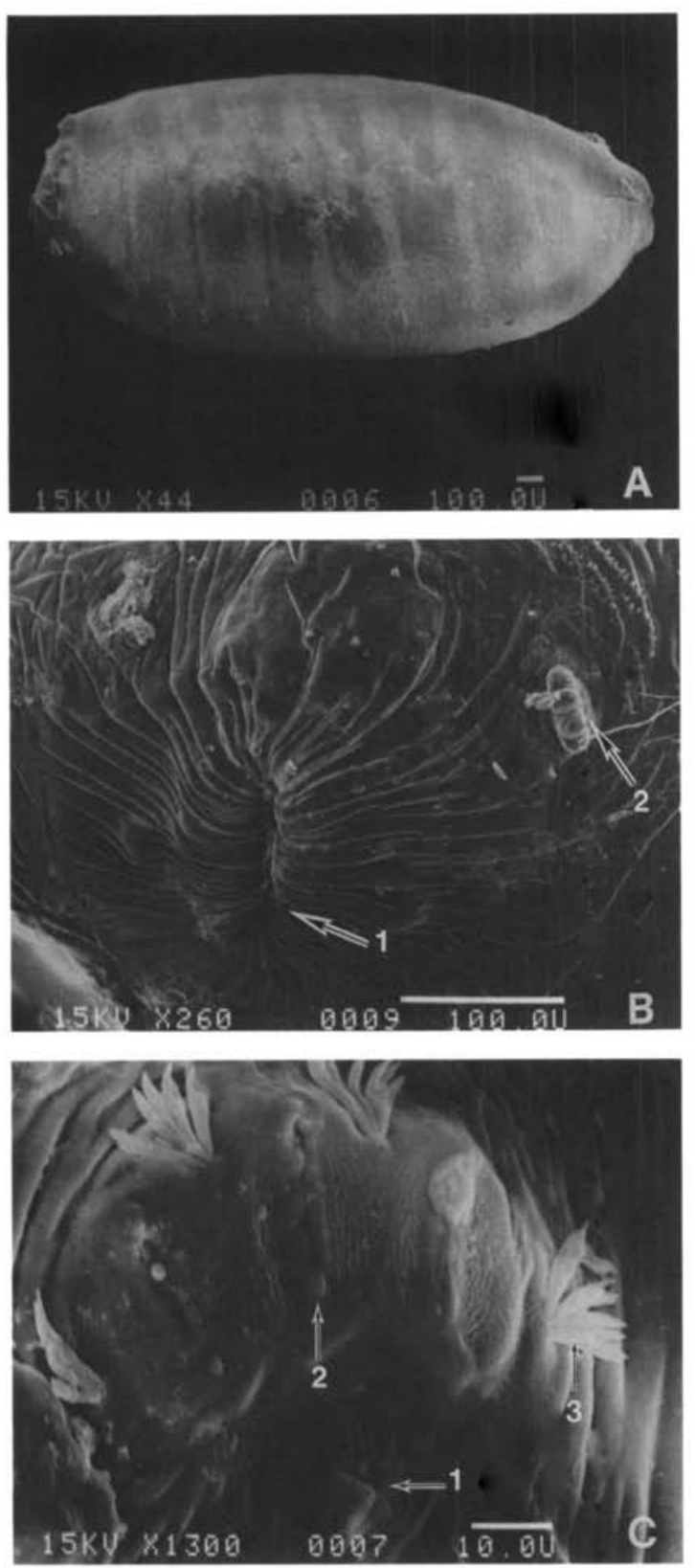

Fig. 10. Puparium of T. nigricornis. (A) Habitus, anterior to right; (B) anterior end, (1) invagination scar, (2) anterior thoracic spiracle; (C) posterior spiracular plate, (1) median ecdysial scar, (2) rima, (3) interspiracular process.

have been reported among nonfrugivorous tephritid larvae examined to date having different food niches (galls, flower head, crowns, roots, or stems) (compare, Phillips 1946; Headrick and Goeden 1990; Goeden and Headrick 1991a, b; Goeden et al. 1993). Thus, the mouthparts and their associated sensory organs apparently are versatile in nonfrugivorous tephritids.
To further understand the basis of the well-documented differential host preferences of these 2 cryptic, sympatric, probably sibling species, and to build further hypotheses about their evolutionary history and host selection, additional, comparative studies on their biology, ecology, and behavior have been completed by us (unpublished data).

\section{Acknowledgments}

We sincerely thank F. L. Blanc, L. E. Carroll, J. A. Teerink, and 1 anonymous reviewer for their helpful reviews of earlier drafts of this article. We also thank Gordon Gordh for his assistance and material support for this study.

\section{References Cited}

Carroll, L. E., and R. A. Wharton. 1989. Morphology of the immature stages of Anastrepha ludens (Diptera: Tephritidae). Ann. Entomol. Soc. Am. 82: 201-214.

Cavender, G. L., and R. D. Goeden. 1982. Life history of Trupanea bisetosa (Diptera: Tephritidae) on wild sunflower in southern California. Ann. Entomol. Soc. Am. 75: 400-406.

1983. On distinguishing Trupanea bisetosa (Coquillett) from T. nigriconis (Coquillett) (Diptera: Tephritidae). Proc. Entomol. Soc. Wash. 85: 275-281.

Foote, R. H. 1960. A revision of the genus Trupanea in America north of Mexico. U.S. Dep. Agric. Tech. Bull. 1214.

Foote, R. H., and F. L. Blanc. 1963. The fruit flies or Tephritidae of California. Bull. Calif. Insect Surv. 7: 1-117.

Foote, R. H., F. L. Blanc, and A. L. Norrbom. 1993. Handbook of the fruit flies (Diptera: Tephritidae) of America North of Mexico. Cornell University Press, Ithaca.

Goeden, R. D. 1987. Life history of Trupanea conjuncta (Adams) on Trixis californica Kellogg in southern California. Pan-Pac. Entomol. 63: 284-291.

1988. Life history of Trupanea imperfecta (Coquillett) on Bebbia juncea (Bentham) Greene in the Colorado Desert of southern California (Diptera: Tephritidae). Pan-Pac. Entomol. 64: 345-351.

Goeden, R. D., and D. H. Headrick. 1991 a. Life history and descriptions of immature stages of Tephritis baccharis (Coquillett) on Baccharis salicifolia (Ruiz and Pavon) Persoon in southern California (Diptera: Tephritidae). Pan-Pac. Entomol. 67: 8698.

1991b. Notes on the biology, hosts, and immature stages of Tomoplagia cressoni Aczél in southern California (Diptera: Tephritidae). Proc Entomol. Soc. Wash. 93: 549-558.

1992. Life history and descriptions of immature stages of Neaspilota viridescens Quisenberry (Diptera: Tephritidae) on native Asteraceae in southern California. Proc. Entomol. Soc. Wash. 94: 59-77.

Goeden, R. D., D. H. Headrick, and J. A. Teerink. 1993. Life history and descriptions of immature stages of Tephritis arizonaensis Quisenberry (Diptera: Tephritidae) on Baccharis sarothroides Gray in southern California. Proc. Entomol. Soc. Wash. 95: 210222. 
Headrick, D. H., and R. D. Goeden. 1990. Description of the immature stages of Paracantha gentilis (Diptera: Tephritidae). Ann. Entomol. Soc. Am. 83: 220-229.

1991. Life history of Trupanea californica Malloch (Diptera: Tephritidae) on Gnaphalium spp. in southern California. Proc. Entomol. Soc. Wash. 93: 559-570.
Phillips, V. T. 1946. The biology and identification of trypetid larvae (Diptera: Tephritidae). Mem. Am. Entomol. Soc. 12: 1-161.

Received for publication 19 July 1994; accepted 6 September 1995. 